\title{
Mucosal-Associated Invariant T Cells as a Possible Target to Suppress Secondary Infections at COVID-19
}

\author{
Roman A. Akasov ${ }^{1,2,3 * t}$ and Evgeny V. Khaydukov ${ }^{1,3 * t}$ \\ ${ }^{1}$ Federal Scientific Research Centre "Crystallography and Photonics" Russian Academy of Sciences, Moscow, Russia, \\ ${ }^{2}$ Laboratory of Biomedical Nanomaterials, National University of Science and Technology "MISIS", Moscow, Russia, ${ }^{3}$ Center \\ of Biomedical Engineering, Institute of Molecular Medicine, Sechenov University, Moscow, Russia
}

Keywords: COVID-19, SARS-CoV-2, mucosal associated invariant T cells, riboflavin, flavin mononucleotide, FMN riboswitch, immunomodulation, cytokines

\section{INTRODUCTION}

Co-infections are of proven importance in the severity of respiratory diseases while their involvement in COVID-19 progression is still little discussed (1). However, one in seven patients with COVID-19 had secondary non-viral infections during hospitalization, and 50\% of non-surviving patients had secondary infection in a retrospective cohort study in Wuhan (2). Severe patients with COVID-19 often need invasive mechanical ventilation that takes a long time (on average 9 days), and can lead to infections acquired in the hospital and on the ventilator (1). The role of gut microbiota in the severity of COVID-19 has been also recently discussed, suggesting that a microbial metabolic process in the gut may affect the production of pro-inflammatory cytokines (3). There are some pathways between the microbiota and the host immune system, including TNF $\alpha$ and IFN $\gamma$ production associated with specific microbial metabolic pathways of palmitoleic acid metabolism and degradation of tryptophan to tryptophol (4), but this area needs further evaluation. Therefore, the study of interactions between the host and microbiota is of great importance for understanding the progression and therapy of COVID-19.

\section{MAIT CELLS ACTIVATION AS A POSSIBLE MECHANISM PARTICIPATING IN COVID-19 PROGRESSION}

Mucosal associated invariant T (MAIT) cells are found in the blood, liver, lungs, and mucosa, protecting against microbial activity and infection (5). MAIT cells can be activated via MR1-dependent and MR1-independent pathways. MR1-independent activation requires cytokines (e.g., IL-12 or IL-18) while MR1-dependent activation needs recognition of small molecules of biosynthesis of vitamin B2 (riboflavin) and B9 (folic acid). Activated MAIT cells rapidly produce pro-inflammatory cytokines including IFN $\gamma, \mathrm{TNF} \alpha$, and IL-17 (6). Typically, MAIT cells are discussed in context of bacterial or fungal infections, as they can induce the immune response when activated with riboflavin precursors in MR1-dependent manner. However, MAIT cells activation was also described for viral infections, including herpes, hepatitis, or lethal influenza $(7,8)$. In the case of viruses, MAIT activation occurred via MR1-independent pathway as a result of cytokines binding (IL-18 in synergy with IL-12, IL-15, and/or interferon- $\alpha / \beta$ ) (9). No information regarding the increased values of IL-18, IL-12, or IL-15 in patients with COVID-19 was found and, therefore, this possible activation pathway requires further study. On the other hand, the role of MAIT cells resident in lung tissue in children with community-acquired pneumonia was demonstrated (10). Immunity profiling showed that MAIT cells from the bronchoalveolar lavages, but not from the blood, actively produced IL-17. It is important that most patients were diagnosed with adenovirus and Mycoplasma pneumoniae 
while neither adenovirus nor mycoplasma synthesize riboflavin. The authors suggested that MAIT cells were probably activated through commensal microorganisms or co-infecting bacteria in combination with inflammatory cytokines (10). Since only MAIT cells resident in lung tissue but not derived from the blood produced IL-17, the contribution of co-infecting bacteria appears to be more important. It should be noted that targeting IL-17 was recently proposed as a strategy to combat acute respiratory distress syndrome in COVID-19 (11). Therefore, we hypothesize the importance of the study of MAIT cells in blood and especially in lungs, given the evidence that the status of $\mathrm{T}$ cells reflects the severity of infection and predict the clinical outcomes in patients with COVID-19 $(12,13)$. Thus, we suggest that activation of MAIT cells in secondary non-viral infection via the MR1-dependent pathway may be a factor that enhances the progression of COVID-19, and IL-17 production may be one of the mediators.

\section{INHIBITION OF RIBOFLAVIN BIOSYNTHESIS IN MICROBIOTA AS A POSSIBLE APPROACH TO PREVENT MAIT ACTIVATION}

Since MR1-dependent activation occurs as a result of recognizing small molecules of riboflavin biosynthesis, inhibition of this pathway appears to be a promising approach to prevent the immune response of MAIT cells. Indeed, an immunomodulatory strategy of herpesviruses that functionally disrupts the immune response was defined for MR1 targeting (14). It was found that riboflavin biosynthesis can be repressed by inhibiting enzymes involved in riboflavin biosynthesis (15) or at the level of transcription through the flavin mononucleotide (FMN) riboswitch (16). The FMN riboswitch is a metabolite-dependent RNA element that directly binds FMN and controls the expression of genes responsible for riboflavin biosynthesis since FMN is riboflavin- $5^{\prime}$-phosphate (17).

There are some synthetic or natural compounds that can inhibit FMN riboswitch. Among them, roseoflavin, a pigment originally isolated from Streptomyces davawensis, was discussed as an antimetabolite analog of riboflavin and FMN with antimicrobial properties (16). The other is 5FDQD, a riboswitchbinding analog of flavin that protects mice against Clostridium difficile infection without inhibiting healthy bowel flora (18). Double-targeting of the Staphylococcus aureus FMN riboswitch with roseoflavin and ribocil- $\mathrm{C}$ demonstrated efficacy in a murine model of MRSA (Methicillin Resistant Staphylococcus Aureus) infection (19).

However, FMN or even riboflavin may be also effective in inhibiting riboflavin biosynthesis. A strategy of the oral supplementation with riboflavin may be proposed, given that some bacteria can switch from biosynthesis to uptake of riboflavin when it is environmentally available. It should be noted that riboflavin supplementation ( $100 \mathrm{mg}$ daily for 3 weeks) in patients with Crohn's disease, a type of inflammatory bowel disease, led to anti-inflammatory effects (20). Activation of innate MAIT cells in inflammatory bowel diseases resulted in a switch in the pattern of cytokine secretion was previously demonstrated (21). Riboflavin supplementation (10 mg/day, p.o) significantly decreased plasma homocysteine, a marker of inflammation and ischemic injury, in the group of elderly people with low riboflavin status (22).

An alternative approach to inhibit overactivation of MAIT cells is a ligand-dependent downregulation of MR1 cell surface expression via retaining MR1 molecules in the endoplasmic reticulum in an immature form (23).

\section{DISCUSSION}

We hypothesize that secondary non-viral infections may enhance the severity of COVID-19 by activating MR1-dependent MAIT cells. MAIT cells promote protection against primary infections through cytokines production (24), as well as mediate protective host responses in sepsis by reducing bacterial burden (25). However, in the case of secondary infections, additive inflammation can exacerbate the situation due to the progression of the cytokine storm. The possible involvement of MAIT cells in the development of undesirable immune response in certain diseases was previously shown (5). Thus, MAIT cells promote inflammation and exacerbate the disease in murine models of arthritis while mice with MR1 deficiency develop a less severe disease compared to control (26). In mice infected with Helicobacter pylori, MAIT cells were expanded in the gastric mucosa and adopted the IL-17A- and IFN- $\gamma$-producing phenotype, resulting in the gastric progression (27). It is important that MAIT cell activation is detected $2 \mathrm{~h}$ after contact with the antigen (28). It should be also noted that MAIT cells are much less frequent in children ( $<2$ y.o.) than in older humans (5). Functional alteration of innate T cells in COVID-19 patients has been described very recently, including a decrease in circulating MAIT cells in blood, which may be a consequence of their recruitment into the airways (29).

If the hypothesis of MR1-dependent MAIT cells activation in secondary infection of COVID-19 is correct, inhibition mechanisms of this activation could be discussed. This can be accomplished by inhibiting the riboflavin biosynthesis in the microbiota (e.g., with roseoflavin or analogs) or by liganddependent downregulation of the MR1 cell surface expression in antigen-presenting cells (e.g., with DB28 or analogs (23)). The first option seems easier to implement since the inhibition of riboflavin biosynthesis pathway can lead to toxicity for microbiota, including pathogen bacteria and yeasts, but not to the host.

We must also point out some arguments that contradict our idea. Thus, neutrophils that are recruited early to sites of infections, including COVID-19 infection, can suppress and prevent overactivation of MAIT cells (30). Since repeated MAIT cells stimulation by cytokines (IL-12 and IL-18) was found to enhance IL-17 production by MAIT cells (31), the patients may not benefit from the treatment that suppresses MR1dependent stimulation. The interactions of MAIT cells with other participants in the immune response are also unclear, as well as the impact of MAIT cells infection at a distant site, i.e., the impact 
of gut MAIT cells on pulmonary infection or vice versa (32). Therefore, we appeal to the biomedical community to test the hypothesis of MR1-dependent MAIT cells activation as a possible therapeutic approach.

\section{AUTHOR CONTRIBUTIONS}

Both authors listed have made a substantial, direct and intellectual contribution to the work, and approved it for publication.

\section{REFERENCES}

1. Cox MJ, Loman N, Bogaert D, O'Grady J. Co-infections: potentially lethal and unexplored in COVID-19. Lancet Microbe. (2020) 1:e11. doi: 10.1016/S2666-5247(20)30009-4

2. Zhou F, Yu T, Du R, Fan G, Liu Y, Liu Z, et al. Clinical course and risk factors for mortality of adult inpatients with COVID-19 in Wuhan, China: a retrospective cohort study. Lancet. (2020) 395:105462. doi: 10.1016/S0140-6736(20)30566-3

3. Kalantar-Zadeh K, Ward SA, Kalantar-Zadeh K, El-Omar EM. Considering the effects of microbiome and diet on SARS-CoV-2 infection: nanotechnology roles. ACS Nano. (2020) 14:5179-82. doi: 10.1021/acsnano.0c 04407

4. Schirmer M, Smeekens SP, Vlamakis H, Jaeger M, Oosting M, Franzosa EA, et al. Linking the human gut microbiome to inflammatory cytokine production capacity. Cell. (2016) 167:1125-36.e8. doi: 10.1016/j.cell.2016.10.020

5. Godfrey DI, Koay HF, McCluskey J, Gherardin NA. The biology and functional importance of MAIT cells. Nat Immunol. (2019) 20:111028. doi: 10.1038/s41590-019-0444-8

6. Xiao X, Cai J. Mucosal-Associated Invariant $\mathrm{T}$ Cells: New Insights into Antigen Recognition and Activation. Front Immunol. (2017) 8:1540. doi: 10.3389/fimmu.2017.01540

7. Ussher JE, Willberg CB, Klenerman P. MAIT cells and viruses. Immunol Cell Biol. (2018) 96:630-41. doi: 10.1111/imcb.12008

8. van Wilgenburg B, Scherwitzl I, Hutchinson EC, Leng T, Kurioka A, Kulicke C, et al. MAIT cells are activated during human viral infections. Nat Commun. (2016) 7:11653. doi: 10.1038/ncomms11653

9. van Wilgenburg B, Loh L, Chen Z, Pediongco TJ, Wang H, Shi $\mathrm{M}$, et al. MAIT cells contribute to protection against lethal influenza infection in vivo. Nat Commun. (2018) 9:4706. doi: 10.1038/s41467-018-0 7207-9

10. Lu B, Liu M, Wang J, Fan H, Yang D, Zhang L, et al. IL-17 production by tissueresident MAIT cells is locally induced in children with pneumonia. Mucosal Immunol. (2020). doi: 10.1038/s41385-020-0273-y. [Epub ahead of print].

11. Pacha O, Sallman MA, Evans SE. COVID-19: a case for inhibiting IL-17? Nat Rev Immunol. (2020) 20:345-6. doi: 10.1038/s41577-020-0328-z

12. Liu Z, Long W, Tu M, Chen S, Huang Y, Wang S, et al. Lymphocyte subset $(\mathrm{CD} 4+, \mathrm{CD} 8+)$ counts reflect the severity of infection and predict the clinical outcomes in patients with COVID-19. I Infect. (2020). doi: 10.1016/j.jinf.2020.03.054. [Epub ahead of print].

13. Diao B, Wang C, Tan Y, Chen X, Liu Y, Ning L, et al. Reduction and functional exhaustion of $\mathrm{t}$ cells in patients with coronavirus disease 2019 (COVID-19). Front Immunol. (2020) 11:827. doi: 10.3389/fimmu.2020.00827

14. McSharry BP, Samer C, McWilliam HEG, Ashley CL, Yee MB, Steain $M$, et al. Virus-mediated suppression of the antigen presentation molecule MR1. Cell Rep. (2020) 30:2948-62.e4. doi: 10.1016/j.celrep.202 0.02 .017

15. Kundu B, Sarkar D, Ray N, Talukdar A. Understanding the riboflavin biosynthesis pathway for the development of antimicrobial agents. Med Res Rev. (2019) 39:1338-71. doi: 10.1002/med.21576

16. Lee ER, Blount KF, Breaker RR. Roseoflavin is a natural antibacterial compound that binds to FMN riboswitches and regulates gene expression. RNA Biol. (2009) 6:187-94. doi: 10.4161/rna.6.2.7727

\section{ACKNOWLEDGMENTS}

RA acknowledges the Ministry of Education and Science of the Russian Federation in the framework of Increase Competitiveness Program of NUST MISiS (No. K42018-052), implemented by a governmental decree dated 16th of March 2013, N 211. EK acknowledges the Ministry of Science and Higher Education within the State assignment FSRC «Crystallography and Photonics $\gg$ RAS.

17. Machtel P, Bakowska-Zywicka K, Zywicki M. Emerging applications of riboswitches - from antibacterial targets to molecular tools. J Appl Genet. (2016) 57:531-41. doi: 10.1007/s13353-01 6-0341-x

18. Blount KF, Megyola C, Plummer M, Osterman D, O'Connell T, Aristoff $\mathrm{P}$, et al. Novel Riboswitch-Binding Flavin Analog That Protects Mice against Clostridium difficile Infection without Inhibiting Cecal Flora. Antimicrob Agents Chemother. (2015) 59:5736-46. doi: 10.1128/AAC.01 282-15

19. Wang H, Mann PA, Xiao L, Gill C, Galgoci AM, Howe JA, et al. Dual-Targeting small-molecule inhibitors of the Staphylococcus aureus FMN riboswitch disrupt riboflavin homeostasis in an infectious setting. Cell Chem Biol. (2017) 24:576-88.e6. doi: 10.1016/j.chembiol.2017.03.014

20. von Martels JZH, Bourgonje AR, Klaassen MAY, Alkhalifah HAA, Sadaghian Sadabad M, Vich Vila A, et al. Riboflavin Supplementation in Patients with Crohn's Disease [the RISE-UP study]. J Crohn's Colitis. (2020) 14:595-607. doi: 10.1093/ecco-jcc/jjz208

21. Serriari N-E, Eoche M, Lamotte L, Lion J, Fumery M, Marcelo P, et al. Innate mucosal-associated invariant T (MAIT) cells are activated in inflammatory bowel diseases. Clin Exp Immunol. (2014) 176:266-74. doi: 10.1111/cei. 12277

22. Tavares NR, Moreira PA, Amaral TF. Riboflavin supplementation and biomarkers of cardiovascular disease in the elderly. $J$ Nutr Heal Aging. (2009) 13:441-6. doi: 10.1007/s12603-009-0 081-2

23. Salio M, Awad W, Veerapen N, Gonzalez-Lopez C, Kulicke C, Waithe D, et al. Ligand-dependent downregulation of MR1 cell surface expression. Proc Natl Acad Sci USA. (2020) 117:10465-75. doi: 10.1073/pnas.20031 36117

24. Hartmann N, Harriff MJ, McMurtrey CP, Hildebrand WH, Lewinsohn DM, Kronenberg M. Role of MAIT cells in pulmonary bacterial infection. Mol Immunol. (2018) 101:155-9. doi: 10.1016/j.molimm.2018.06.270

25. Trivedi S, Labuz D, Anderson CP, Araujo C V., Blair A, Middleton EA, et al. Mucosal-associated invariant $\mathrm{T}$ (MAIT) cells mediate protective host responses in sepsis. bioRxiv. (2020). doi: 10.1101/2020.02.05.9 35866. [Epub ahead of print].

26. Chiba A, Tajima R, Tomi C, Miyazaki Y, Yamamura T, Miyake S. Mucosal-associated invariant $\mathrm{T}$ cells promote inflammation and exacerbate disease in murine models of arthritis. Arthritis Rheum. (2012) 64:15361. doi: 10.1002 /art.33314

27. D'Souza C, Pediongco T, Wang H, Scheerlinck J-PY, Kostenko L, Esterbauer $\mathrm{R}$, et al. Mucosal-Associated Invariant T Cells Augment Immunopathology and Gastritis in Chronic Helicobacter pylori Infection. J Immunol. (2018) 200:1901-16. doi: 10.4049/jimmunol.1701512

28. Chen Z, Wang H, D'Souza C, Sun S, Kostenko L, Eckle SBG, et al. Mucosal-associated invariant T-cell activation and accumulation after in vivo infection depends on microbial riboflavin synthesis and costimulatory signals. Mucosal Immunol. (2017) 10:58-68. doi: 10.1038/mi.2 016.39

29. Jouan Y, Guillon A, Gonzalez L, Perez Y, Ehrmann S, Ferreira $\mathrm{M}$, et al. Functional alteration of innate $\mathrm{T}$ cells in critically ill Covid-19 patients. medRxiv. (2020). doi: 10.1101/2020.05.03.200 89300. [Epub ahead of print]. 
30. Schneider M, Hannaway RF, Lamichhane R, Harpe SM, Tyndall JDA, Vernall AJ, et al. Neutrophils suppress mucosal-associated invariant T cells in humans. Eur J Immunol. (2020) 50:643-55. doi: 10.1002/eji.201948394

31. Böttcher K, Rombouts K, Saffioti F, Roccarina D, Rosselli M, Hall A, et al. MAIT cells are chronically activated in patients with autoimmune liver disease and promote profibrogenic hepatic stellate cell activation. Hepatology. (2018) 68:172-86. doi: 10.1002/hep.29782

32. Wong EB, Ndung'u T, Kasprowicz VO. The role of mucosal-associated invariant $\mathrm{T}$ cells in infectious diseases. Immunology. (2017) 150:4554. doi: $10.1111 / \mathrm{imm} .12673$
Conflict of Interest: The authors declare that the research was conducted in the absence of any commercial or financial relationships that could be construed as a potential conflict of interest.

Copyright (๑) 2020 Akasov and Khaydukov. This is an open-access article distributed under the terms of the Creative Commons Attribution License (CC BY). The use, distribution or reproduction in other forums is permitted, provided the original author(s) and the copyright owner(s) are credited and that the original publication in this journal is cited, in accordance with accepted academic practice. No use, distribution or reproduction is permitted which does not comply with these terms. 